\title{
RUSHTON BODIES: A RARE ENTITY IN RADICULAR CYST
}

Shubhangi Khandekar ${ }^{1}$, Alka Dive², Divya Sao ${ }^{3}$, Anand Rajderkar ${ }^{4}$

\section{HOW TO CITE THIS ARTICLE:}

Shubhangi Khandekar, Alka Dive, Divya Sao, Anand Rajderkar. "Rushton Bodies: A Rare Entity in Radicular Cyst". Journal of Evolution of Medical and Dental Sciences 2014; Vol. 3, Issue 05, February 03; Page: 1156-1159, DOI: $10.14260 /$ jemds/2014/1960

ABSTRACT: Radicular cyst is the most common inflammatory odontogenic cyst. It is a consequence to pulp necrosis of carious teeth. In this case report, we present a rare case of radicular cyst with Rushton bodies in a 42 years male patient.

KEYWORDS: Inflammatory cyst, Radicular cyst, Rushton bodies.

INTRODUCTION: Cyst is defined as "a pathological cavity having fluid, semifluid or gaseous contents and which are not created by the accumulation of pus". Most cysts but not all, are lined by epithelium. ${ }^{1}$ The term cyst is derived from the Greek word Kystis meaning sac or bladder. ${ }^{2}$

Radicular cysts are the most common inflammatory cysts and arise from the epithelial residues in the periodontal ligament as a result of periapical periodontitis following death and necrosis of the pulp ${ }^{1}$. They may also be found on the lateral aspects of the roots in relation to lateral accessory root canals. Quite often a radicular cyst remains behind in the jaws after removal of the offending tooth and this is referred to as a residual cyst. ${ }^{3}$ It is the most common cystic lesion in the jaws. The high frequency of occurrence of cyst is in maxillary anterior region. It commonly occurs at an age between third and fifth decades of life. ${ }^{1}$

CASE REPORT: A 42 years old male patient reported to the department with a chief complaint of pain in upper front region of jaw since 15 days. Pain was dull and intermittent. Patient had a history of an accident 20 years back that lead to discoloration of maxillary right lateral incisor over a period of time.

Intra-oral examination revealed a single diffuse swelling on the palate of approximately $2 \times 4$ $\mathrm{cm}$ in size extending from 15 to 22 region. Swelling was oval in shape, soft in consistency and of normal mucosal color. On palpation, swelling was non tender. The vitality test was negative with maxillary right lateral incisor.

Radiographic examination revealed a radiolucent area which was well defined, roughly oval in shape of approximately $2 \times 4 \mathrm{~cm}$ in size and was extending from maxillary right second premolar to maxillary left lateral incisor. Divergence was seen between the roots of maxillary right lateral incisors and maxillary canine.

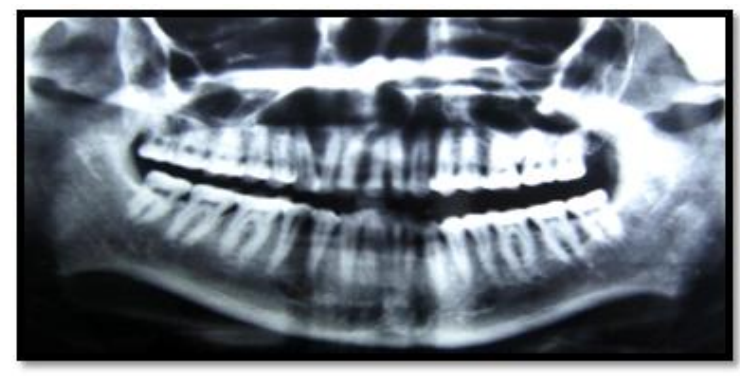

Figure - 1 
On correlating the clinical \& radiographical findings, the case was provisionally diagnosed as "radicular cyst".

After routine hematological investigation, the patient underwent root canal treatment of maxillary right lateral incisor and enucleation of the cystic lesion was done under local anesthesia. Specimen was sent for histopathological examination.

Gross examination revealed a soft tissue specimen which was grayish black in color, oval in shape, of approximately $2 \times 4 \mathrm{~cm}$ in size and soft to firm in consistency with rough surface texture. Cut section revealed a cystic sac.

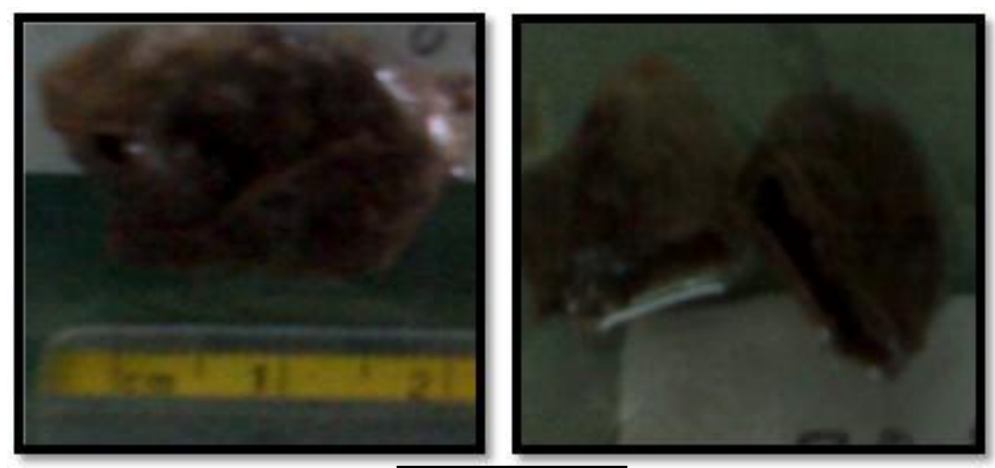

Figure - 2

Microscopic examination of $\mathrm{H} \& \mathrm{E}$ stained section showed cystic lumen with thin lining of non-keratinized stratified squamous epithelium of variable thickness. The connective tissue capsule consisted of fibrocellular stroma with dense chronic inflammatory cell infiltrate chiefly of lymphocytes and plasma cells. Endothelial lined blood capillaries were present few of which were engorged with RBC's. Numerous extravasated RBC's were also seen at periphery. Rushton bodies were seen within the epithelial lining.
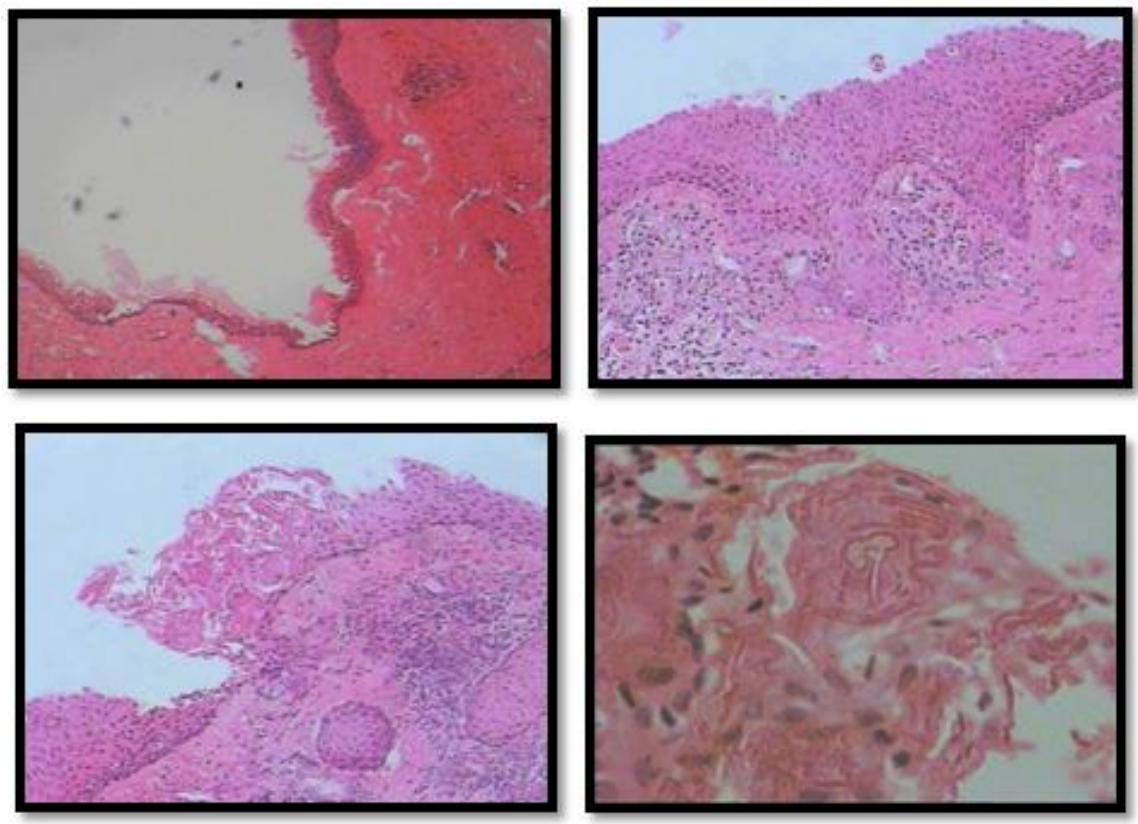

Figure - 3: H \& E Stained Sections 
These Rushton bodies were positive with Papanicolaou (PAP) \& Masson's Trichrome stains. PAP stain showed pink color, while with Masson's Trichrome they appeared red in color.

Based on clinical, radiological and histopathological findings, diagnosis of "radicular cyst with Rushton bodies" was made.

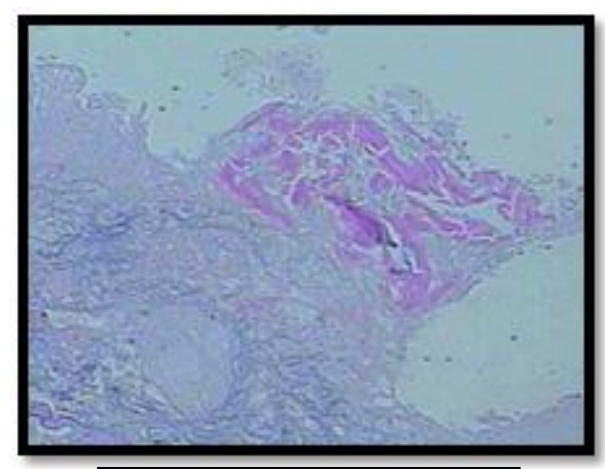

Figure - 4: Pap Stain

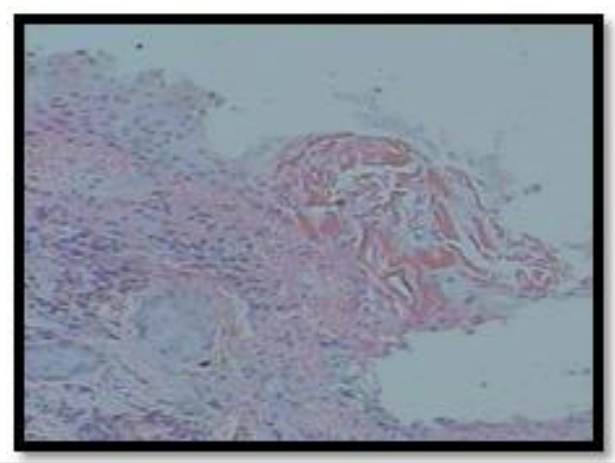

Figure - 5. Masson's Trichrome Stain

DISCUSSION: Usually, radicular cysts are symptomless and are discovered by chance when periapical radiographs are taken of teeth with non-vital pulps. The radiological differential diagnosis of radicular cyst includes periapical granuloma, surgical defect or periapical scar, periapical cementoosseous dysplasia, Traumatic Bone Cyst. It occasionally includes odontogenic tumors, giant cell lesions, metastatic disease and primary osseous tumors.1,4

Histopathologically, almost all radicular cysts are lined wholly or in part by non-keratinized stratified squamous epithelium. These linings may be discontinuous in part and range in thickness from one to 50 cell layers. The epithelial linings may be proliferating and show arcading with an intense associated inflammatory process or be quiescent and fairly regular with a certain degree of differentiation. The inflammatory cell infiltrate in the proliferating epithelial linings consists predominantly of polymorphonuclear leucocytes whereas the adjacent fibrous capsule is infiltrated mainly by chronic inflammatory cells. In some cases of radicular cysts cholesterol clefts, Rushton bodies and pulse/seed granulomas are occasionally seen.

Rushton bodies within the epithelium in odontogenic cyst were first described in detail by MA Rushton and hence are often referred to as Rushton bodies. ${ }^{6}$ These hyaline bodies are found in approximately $10 \%$ of periapical cysts. However, available data from published studies suggests a total incidence of $8 \% .^{6}$ The bodies occur -only in the epithelium or on its surface and are irregularly distributed.1,5 They are exclusively seen in odontogenic cysts and not seen in non-odontogenic cysts such as nasopalatine duct cyst and fissural cysts. A single case of Rushton Bodies in plexiform ameloblastoma has been reported in the lesions other than jaw cysts. ${ }^{6}$

Microscopically, on histopathological examination Rushton bodies appear as structures tucked within the epithelium that are acellular, eosinophilic, linear, straight or curved or hairpin shaped, circular or polycyclic forms often with a granular core and at times laminated concentrically. They were refractile but not birefringent. ${ }^{6}$

Rushton bodies give negative result with Periodic acid Schiff and Von Kossa's stains for mucopolysaccharides and calcium respectively. Although Rushton bodies shows strong positivity 
with Papanicolaou stain, Masson's Trichrome, Orcein stains and Prussian blue. Rushton bodies may also show positivity with Gomori stain. 5, 6

According to Rushton, Rushton bodies originated from odontogenic epithelium as a keratin product. Some authors postulated that they were of hematogenous origin or thought that they were formed due to elastotic degeneration. Alternatively, they were also thought to be formed as a cellular reaction to extravasated serum. ${ }^{6}$

In our case, Rushton bodies within the epithelial lining appeared as acellular, eosinophilic and curvilinear shaped structures. These Rushton bodies showed positivity with Papanicolaou (Pap) \& Masson's Trichrome stains.

CONCLUSION: Radicular cyst usually goes unobserved and is discovered accidently in the radiographs. This paper represents a case of radicular cyst showing Rushton bodies which is very rare and the clinical significance of Rushton bodies is still not clear in the present scenario.

\section{REFERENCES:}

1. Shear M \& Speight PM. Radicular \& Residual Cyst. Cysts of the Oral Regions, $3^{\text {rd }}$ edtion, Boston, Wright, 1992.136-70.

2. Nair PNR. New perspectives on radicular cysts: do they heal? International Endodontic Journal (1998) 31.155-160.

3. Suhail Latoo, Ajaz. A. Shah, Suhail. M. Jan, S Qadir, I Ahmed, A.R. Purra, A.H Malik. Radicular Cyst. www.Jkscience.Org.Vol. 11(4), Oct-December 2009.

4. Rajendran R. Cysts \& tumors of odontogenic origin. Shafer's text book of oral pathology. $5^{\text {th }}$ edition. Elsevier, 2010.268-269.

5. Rushton MA. Hyaline bodies in the epithelium of dental cysts. Proc R Soc Med 1955; 48: 407-9.

6. Sunitha Jacob. Rushton bodies or hyaline bodies in radicular cyst -a morphologic curiosity. IJPM. Vol. 53. Oct- Dec. 2010.

\section{AUTHORS:}

1. Shubhangi Khandekar

2. Alka Dive

3. Divya Sao

4. Anand Rajderkar

\section{PARTICULARS OF CONTRIBUTORS:}

1. Professor, Department of Oral Pathology, VSPM's Dental College and Research Centre, Nagpur.

2. HOD \& Professor, Department of Oral Pathology, VSPM's Dental College and Research Centre, Nagpur.

3. PG Student, Department of Oral Pathology, VSPM's Dental College and Research Centre, Nagpur.

4. PG Student, Department of Oral Pathology, VSPM's Dental College and Research Centre, Nagpur.

\section{NAME ADDRESS EMAIL ID OF THE} CORRESPONDING AUTHOR:

Dr.Divya Sao,

D/o Dr.K.K.Sao,

KRS Hospital, Sipat chauk,

Sarkanda, Bilaspur(C.G), 495001.

E-mail: anand.p.rajderkar@gmail.com

Date of Submission: 07/01/2014.

Date of Peer Review: 08/01/2014.

Date of Acceptance: 23/01/2014.

Date of Publishing: 29/01/2014. 